\title{
Simulating the Health Impact of Particulate Emissions from Transport Fuels Using Multipath Particle Deposition Model (MPPD)
}

\author{
Bornes C. Mosonik, Joshua K. Kibet”, Silas M. Ngari \\ Department of Chemistry, Egerton University, Egerton, Kenya \\ Email: ‘jkibet@egerton.ac.ke
}

How to cite this paper: Mosonik, B.C., Kibet, J.K. and Ngari, S.M. (2019) Simulating the Health Impact of Particulate Emissions from Transport Fuels Using Multipath Particle Deposition Model (MPPD). Open Journal of Modelling and Simulation, 7, 115-124.

https://doi.org/10.4236/ojmsi.2019.72006

Received: March 11, 2019

Accepted: April 22, 2019

Published: April 25, 2019

Copyright $\odot 2019$ by author(s) and Scientific Research Publishing Inc. This work is licensed under the Creative Commons Attribution-NonCommercial International License (CC BY-NC 4.0). http://creativecommons.org/licenses/by-nc/4.0/

\begin{abstract}
Transport fuels emit particulates of varying chemical nature and size. These particulates are known to cause respiratory problems of medical concern. The need to simulate the breathing characteristics of particulates generated from combustion events is very important in estimating the respiratory clearance of these particles. Consequently, this study examines the nature of particulate matter from the pyrolysis of a mixture Croton megalocarpus biodiesel and fossil diesel, and pure biodiesel. The study was explored at an optimum temperature of $600^{\circ} \mathrm{C}$ in an inert nitrogen environment at a contact time of $2 \mathrm{sec}$. Scanning electron microscope was used to examine the surface of the particulates. Multiple-Path Particulate Dosage (MPPD Ver. 3.04) model was used to determine the breathing phenomena of infants, teenagers and adults at different orientations. Co-pyrolytic Char particulates and pyrolytic croton thermal char were classified as ultrafine, $\mathrm{PM}_{0.03}$ and $\mathrm{PM}_{0.02}$ respectively. The MPPD model results indicated that ultrafine particles tend to be deposited in pulmonary regions more than head and trachea regions, due to high probability of diffusibiliy of ultrafine particles. It was noted that 8 years old exhibits a unique trend with high total deposition and poor respiratory clearance when compared to an adult of 21 years old.
\end{abstract}

\section{Keywords}

Particulate Emissions, Respiratory Clearance, MMPD, Combustion Events

\section{Introduction}

The health implications occasioned by inhaling fuel particulate matter have been a medical area of concern for decades due to physico-chemical nature of the par- 
ticulates and size. Exposure to particulate matter has been noted as the major cause of cardiovascular diseases. Conventionally, that mortality from air pollution drastically reduces human life-life span. The long term exposure to PM concentrations above WHO guidelines $\left(10 \mathrm{ug} \cdot \mathrm{m}^{-3}\right)$ is known in literature to initiate elevated dangers of mortality, particularly cardiovascular disease mortality [1].

The by-products of pyrolysis include various particulate matters such as liquid droplets, aerosols, soot, smoke, fumes, ash and solid mixtures [2]. Particulate matter is classified according to size mainly because of the different health effects associated with them. Particulate matter that has an aerodynamic diameter of about 2.5 is classified as $\mathrm{PM}_{2.5}$ while those with 10 micrometers and less are classified as $\mathrm{PM}_{10}$ [3]. Particulate matter $\mathrm{PM}_{2.5}$ is ultrafine and more toxic than $\mathrm{PM}_{10}$, because they have high penetration power deep in the lungs and/or alveolar [4]. A global study from 1990 to 2015 on mortality rates attributed to ambient air pollution reported that ambient $\mathrm{PM}_{2.5}$ was fifth-ranking mortality risk factor in 2015 [5]. Furthermore, research has shown that $\mathrm{PM}_{10}$ or $\mathrm{PM}_{2.5}$ can reside in the lungs and result in mild to severe illness and could cause serious illnesses and life threatening ailments [6] [7]. Several epidemiological studies have shown that continuous exposure to high concentrations of PM especially ultrafine ones has a correlation with human respiratory and cardiovascular health risks [8] [9] [10] [11]. Thus, the quantification of PM deposition and their clearance in the human air-pathways are vital for evaluating health risks. Additionally, the rate of elimination of PM through processes such as body metabolism, chemical action and exhalation also affected the amount of PM clearing in the respiratory system.

In order to have a clear understanding on aerosol deposition in the lungs of humans and animals used in non-clinical studies, a number of computational models have been developed [12]. Retention of inhaled particulate matter in human lungs is an important parameter of health risks, however; it is not easily estimated by conventional means. Therefore, particulate deposition models have been designed which can accurately predict the deposition of particles in human lungs. Multiple-Path Particle Dosimetry (MPPD) Model version 3.04 is such an important model PM deposition [13]. In MPPD, airway structures of infants, children and adults were considered in the study. In general, the deposition of PM in the body tissues is evaluated by their diffusion rate from lung surface across epithelium cells and their retention in the body tissues with the aim of estimating the load burden in the respiratory system across most ages-infants ( 3 months old), children (8 years) and adults (21 years).

\section{Methodology}

\subsection{The Combustion Reactor System}

A Thermo-Scientific heater, USA, with an internal heating compartment of dimensions $14 \mathrm{~cm} \times 12 \mathrm{~cm} \times 13 \mathrm{~cm}$ was used in this study to generate particulate 
emissions for selected transport fuels. The heater was fitted with a temperature regulating knob to regulate the temperature form ambient to $1000^{\circ} \mathrm{C}$. The set up for this study is reported in Figure 1 as reported elsewhere [14].

Fifty (50 mg) of bio-diesel and/or commercial diesel was poured into the quartz reactor housed inside a furnace (Figure 1). The temperature was then set at $600^{\circ} \mathrm{C}$ to simulate the pyrolytic conditions in an internal combustion engine. The flow rate of the pyrolysis gas $\left(\mathrm{N}_{2}\right)$ was set at $2.0 \mathrm{~s}$. This translates to a gas delivery of $147 \mathrm{~cm}^{3} \cdot \mathrm{min}^{-1}$ according to the expression reported by Kibet and his co-workers [14]. Particulate emissions were collected using a clean glass at the end of the vent as shown in Figure 1. The particulates which stuck on the glass were transferred into an amber vial using a clean glass rod and taken to the laboratory for microscopy analysis.

\subsection{Scanning Electron Microscopy Analysis and Particulate Distribution Using Image J}

About $3 \mathrm{mg}$ of particulate matter was introduced into $1 \mathrm{~mL}$ methanol and copper grids dipped into the prepared particulate matter. Twisters were used to pick the gold grids from the char sample. The sample was embedded to aluminium SEM stubs with carbon tape. Samples were subsequently gold coated in a Quorum Q150 RES sputter coater [15]. The grids were allowed to dry in air before putting them into the analysis chamber of a Zeiss Ultra Plus (Germany) field emission gun scanning electron microscope (FEG SEM) [16].

Image $J$ computational code was used to determine the particulate size of the particulate matter evolved from the burning of biodiesel, and biodiesel fossil mixture, and a distribution curve of particulate size was then prepared using Igor graphing software (Igor ver. 5.0). The mean sizes of the char particulates at $600^{\circ} \mathrm{C}$ were then reported. Image $\mathrm{J}$ computational code is a highly intelligent software which apart from measuring the particulate size of particulates also generates the mean and the standard deviation of the particulates [14].

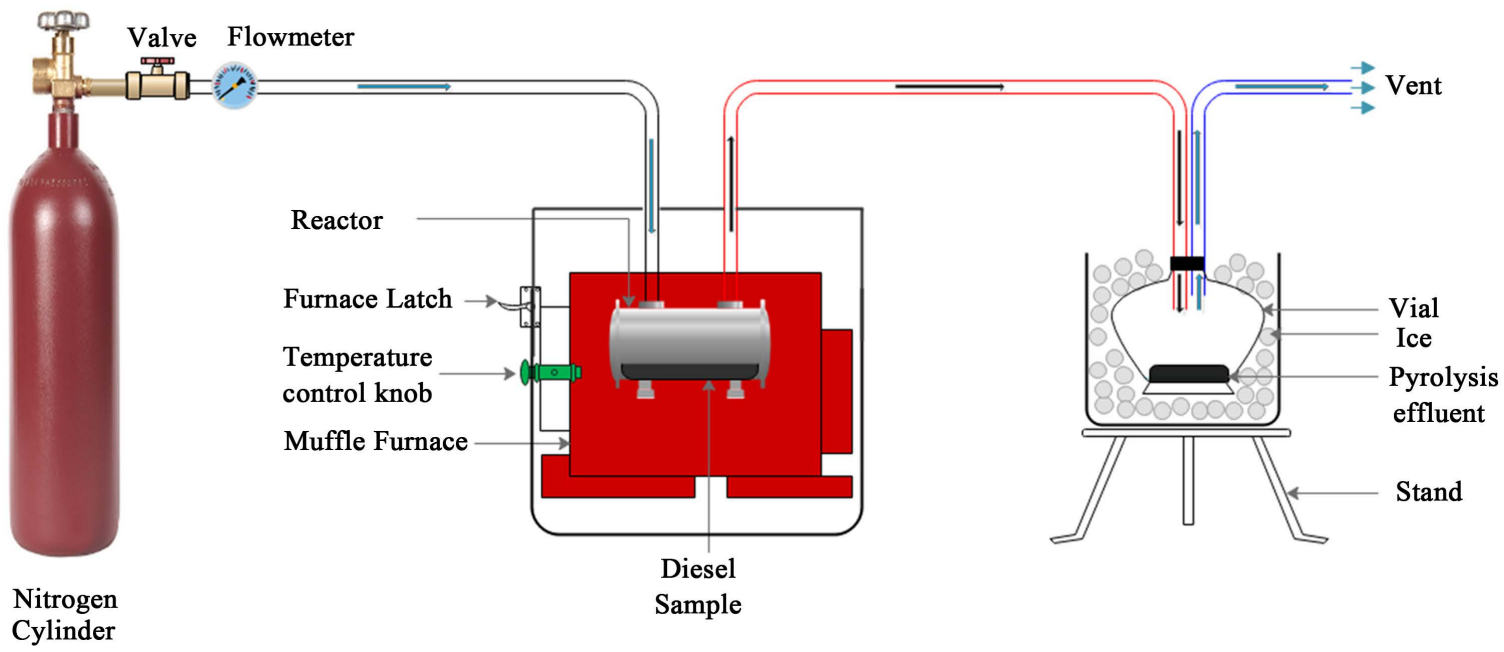

Figure 1. Reactor assembly and gas-phase trapping apparatus. 


\subsection{Respiratory Tract Deposition Model}

Deposition for biodiesel blend emission was predicted using MPPDV3.04 model. The age specific symmetric lung model [17] [18] was used with input parameters such as airway morphometry, inhalant properties, exposure conditions and deposition. The data obtained by authors in previous research, reported that the particulate matter for co-pyrolysis of Croton megalocarpus biodiesel blend and neat commercial diesel were classified as ultrafine, $\mathrm{PM}_{0.03}[14]$ and $\mathrm{PM}_{0.02}$. These particulate sizes were used to model the deposition of particulate matter in MPPD model in human beings for ages 3 months, 8 years and 21 yrs. Other input parameters were not available experimentally and default values in the MPPD software were used. The default settings were applied because experimental parameters were not available. Nonetheless, the simulated values used as defaults are considered to be very close to experimental values for the purpose of simulating breathing scenarios in humans.

\section{Results and Discussion}

In this work, data on the particulate matter emissions of co-pyrolysis of croton biodiesel blend (binary diesel) and fossil diesel is reported. The central point of this investigation is the analysis of particulate matter emission from the co-pyrolysis of Croton megalocarpus biodiesel and fossil diesel. Of principle focus was to classify the particulate matter emitted by co-pyrolysis of Croton megalocarpus biodiesel blend suspected to be the architects of a number of health and environmental problems. It is known that the particulate matter of $\mathrm{PM}_{2.5}$ is ultrafine and more fatal than $\mathrm{PM}_{10}$ because they have high penetration ability deep in the lungs and or alveolar [4]. Computational deposition model was used to understand more on particulate matter transportation into the respiratory system.

\section{Respiratory Tract Deposition Model for Co-Pyrolysis Croton megalocarpus Biodiesel Blend}

The MPPD Ver.3.04 model by Applied Research Associates Inc., Albuquerque, New Mexico, USA was used to predict particle deposition fractions. MPPD software calculates multiple flow paths to multiple airways at any instant.

The MPPD model showed that the deposition fractions for biodiesel blend emissions, predicted for infants (Figure 2(a)), 8 year old (Figure 3(b)) and 21 year old (Figure 4(a)) varied with particle size in various respiratory sections (head- $\mathrm{H}$, trachea and bronchioles (TB) and pulmonary $(\mathrm{P})$ as shown in Figures 2-4. The MPPD infant (3 months) for particulate of geometrical diameter $32 \mathrm{~nm}$ showed that the fractional deposition were $0.1260,0.2322$ and 0.4220 for head, trachea and bronchi and pulmonary respectively. The total lung deposition was 0.7802. On the other hand, the total deposition fraction for particulates of geometrical diameter $22 \mathrm{~nm}$ was 0.8177 (Figure 2(b)).

In the case of 8 years old, the depositions were predicted to be $0.0949,0.1645$ 
Region: Entire Lung

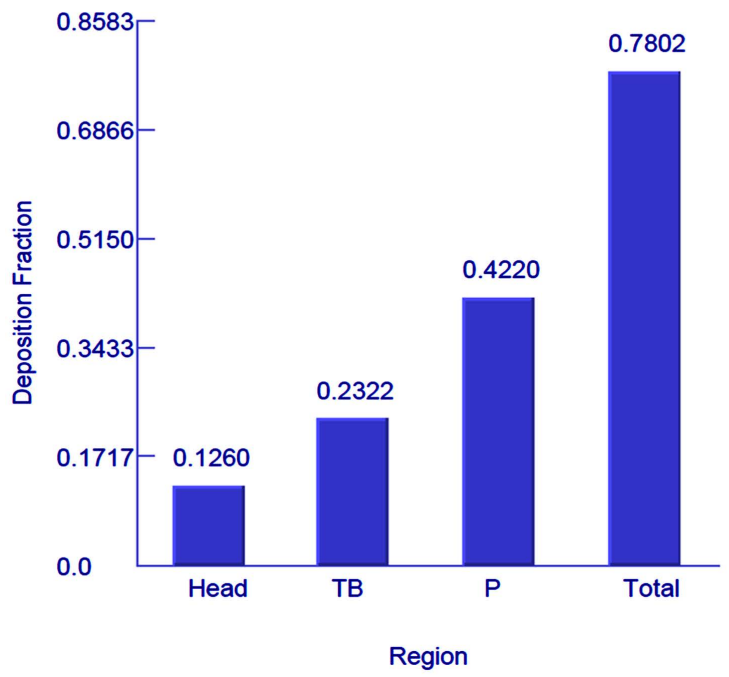

(a)

Region: Entire Lung

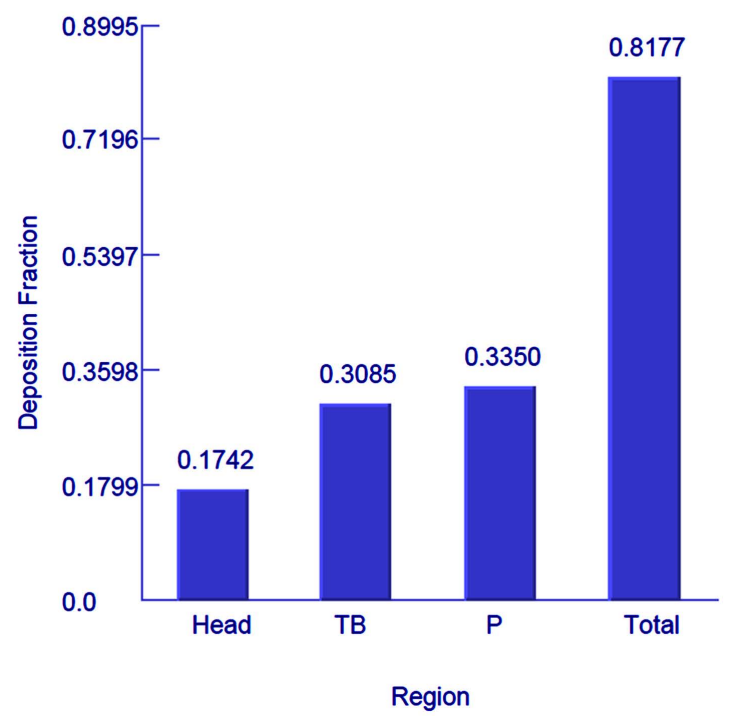

Species \& Model Info:

Species/Geometry: Child Symmetric 3-month FRC Volume: $18.60 \mathrm{ml}$

Head Volume: $2.45 \mathrm{ml}$ Breathing Route: nasal

Breathing Parameters: Tidal Volume: $30.44 \mathrm{ml}$

Breathing Frequency: 39.00 1/min

Inspiratory Fraction: 0.50

Pause Fraction: 0.00

Particle Properties:

Diameter: CMD: $0.0300 \mu \mathrm{m}$

GSD: 1.00

Concentration: $1.00 \mathrm{mg} / \mathrm{m}^{\wedge} 3$
Species \& Model Info:

Species/Geometry: Child Symmetric 3-month FRC Volume: $18.60 \mathrm{ml}$ Head Volume: $2.45 \mathrm{ml}$

Breathing Route: nasal

Breathing Parameters:

Tidal Volume: $30.44 \mathrm{ml}$

Breathing Frequency: $39.001 / \mathrm{min}$

Inspiratory Fraction: 0.50

Pause Fraction: 0.00

Particle Properties:

Diameter: CMD: $0.0200 \mu \mathrm{m}$

GSD: 1.00

Concentration: $1.00 \mathrm{mg} / \mathrm{m}^{\wedge} 3$

(b)

Figure 2. (a) Regional respiratory tract deposition fraction from the Multipath Particle Deposition (MPPD) model version 3.04, for particles with count medium diameter (CMD) of $32 \mathrm{~nm}$ having a geometric standard deviation (GSD) of $1 \mathrm{~nm}$ inhaled by an infant; (b) Regional respiratory tract deposition fraction from the Multipath Particle Deposition (MPPD) model version 3.04, for particles with count medium diameter (CMD) of $22 \mathrm{~nm}$ having a geometric standard deviation (GSD) of $1 \mathrm{~nm}$ inhaled by an infant

and 0.5608 with the total deposition being 0.8202 (Figure 3(a)). The smaller particulates $(22 \mathrm{~nm})$ appeared to have been retained in excess of $\sim 4 \%$ in comparison to the relatively larger particulates $(32 \mathrm{~nm})$. Evidently, the highest fractions of PM were deposited in the pulmonary region across all the ages considered. This could be attributed to higher flow rates and low size range $(0.001$ - 
Region: Entire Lung

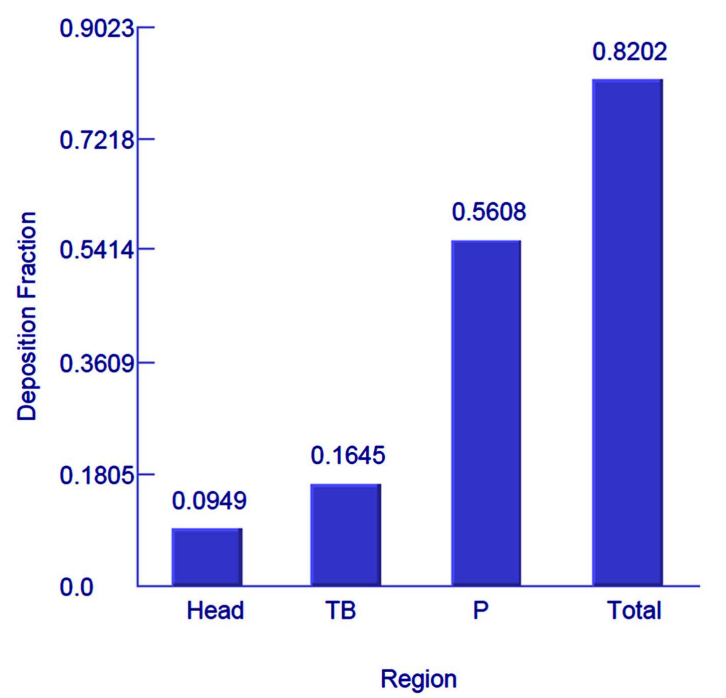

Species \& Model Info Species/Geometry: Child Symmetric 8-year FRC Volume: $740.42 \mathrm{ml}$ Head Volume: $21.03 \mathrm{ml}$ Breathing Route: nasal

Breathing Parameters: Tidal Volume: $278.20 \mathrm{ml}$ Breathing Frequency: 17.00 1/min Inspiratory Fraction: 0.50 Pause Fraction: 0.00 Particle Properties: Diameter: CMD: $0.0300 \mu \mathrm{m}$ GSD: 1.00

Concentration: $1.00 \mathrm{mg} / \mathrm{m}^{\wedge} 3$

(a)

Region: Entire Lung

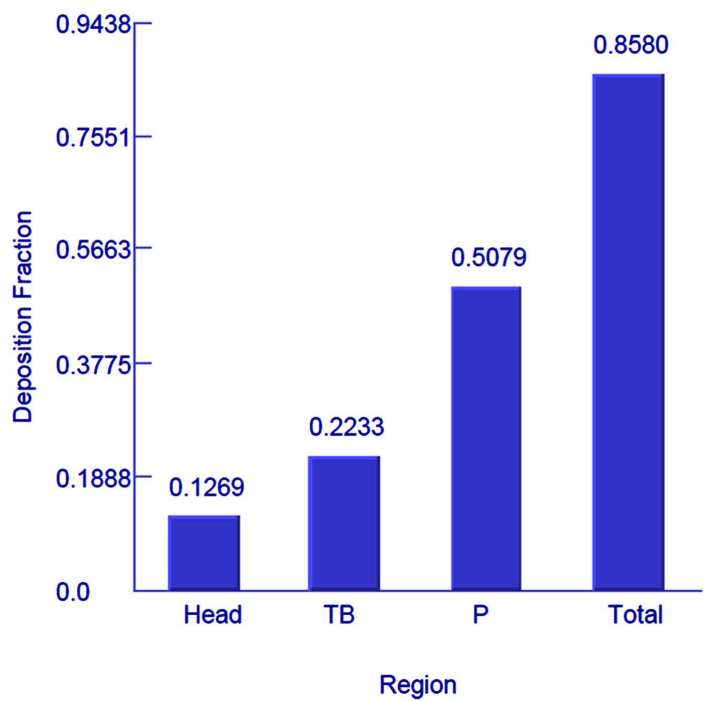

(b)
Species \& Model Info: Species/Geometry: Child Symmetric 8-year FRC Volume: $740.42 \mathrm{ml}$ Head Volume: $21.03 \mathrm{ml}$ Breathing Route: nasal Breathing Parameters: Tidal Volume: $278.20 \mathrm{ml}$ Breathing Frequency: 17.00 1/min Inspiratory Fraction: 0.50 Pause Fraction: 0.00

Particle Properties: Diameter: CMD: $0.0200 \mu \mathrm{m}$ GSD: 1.00 Concentration: $1.00 \mathrm{mg} / \mathrm{m}^{\wedge} 3$

Figure 3. (a) Regional respiratory tract deposition fraction from the Multipath Particle Deposition (MPPD) model version 3.04, for particles with count medium diameter (CMD) of $32 \mathrm{~nm}$ having a geometric standard deviation (GSD) of $1 \mathrm{~nm}$ inhaled by an 8 years old; (b) Regional respiratory tract deposition fraction from the Multipath Particle Deposition (MPPD) model version 3.04, for particles with count medium diameter (CMD) of $22 \mathrm{~nm}$ having a geometric standard deviation (GSD) of $1 \mathrm{~nm}$ inhaled by an 8 years old.

$0.01 \mu \mathrm{m})$ distributions having high residence time in the lower respiratory tract. Similar observations were made by [19].

The total deposition in the lungs appears not to be a function of age because there appears to be no linear correlation of deposition with the age bracket. The 
Region: Entire Lung

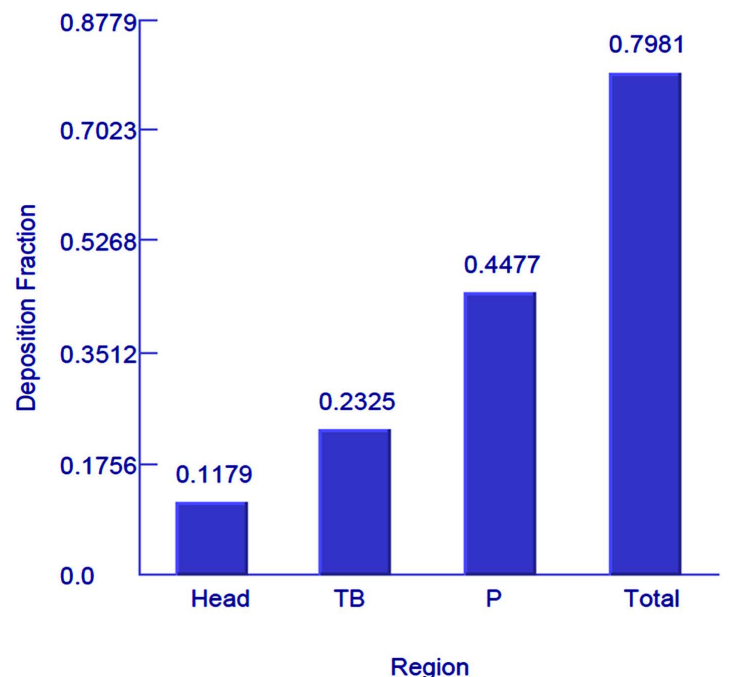

(a)
Species \& Model Info: Species/Geometry: Child Symmetric 21-year FRC Volume: $2792.57 \mathrm{ml}$ Head Volume: $42.27 \mathrm{ml}$ Breathing Route: nasal Breathing Parameters: Tidal Volume: $477.20 \mathrm{ml}$ Breathing Frequency: $14.001 / \mathrm{min}$ Inspiratory Fraction: 0.50 Pause Fraction: 0.00

Particle Properties: Diameter: CMD: $0.0200 \mu \mathrm{m}$ GSD: 1.00 Concentration: $1.00 \mathrm{mg} / \mathrm{m}^{\wedge} 3$

Region: Entire Lung

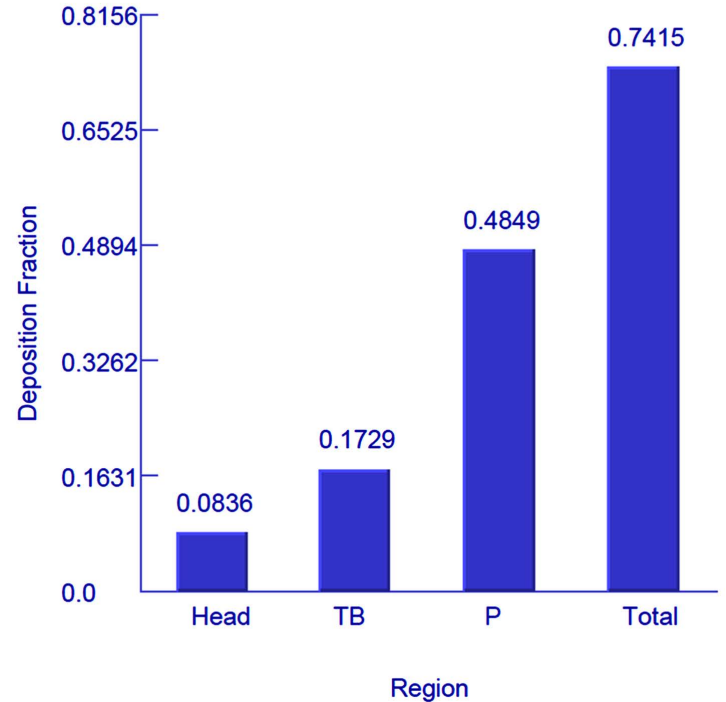

Species \& Model Info: Species/Geometry: Child Symmetric 21-year FRC Volume: $2792.57 \mathrm{ml}$

Head Volume: $42.27 \mathrm{ml}$ Breathing Route: nasal

Breathing Parameters: Tidal Volume: $477.20 \mathrm{ml}$ Breathing Frequency: $14.001 / \mathrm{min}$ Inspiratory Fraction: 0.50 Pause Fraction: 0.00 Particle Properties: Diameter: CMD: $0.0300 \mu \mathrm{m}$ GSD: 1.00 Concentration: $1.00 \mathrm{mg} / \mathrm{m}^{\wedge} 3$

(b)

Figure 4. (a). Regional respiratory tract deposition fraction from the Multipath Particle Deposition (MPPD) model version 3.04, for particles with count medium diameter (CMD) $22 \mathrm{~nm}$ with a geometric standard deviation (GSD) of $1 \mathrm{~nm}$ inhaled by a 21 years old; (b) Regional respiratory tract deposition fraction from the Multipath Particle Deposition (MPPD) model version 3.04, for particles with count medium diameter (CMD) 32 $\mathrm{nm}$ with a geometric standard deviation (GSD) of $1 \mathrm{~nm}$ inhaled by a 21 years old.

probable reason for this, could be that 8 years old population tend to be highly active (high respiration) and spend most of their time outdoors hence they breathe more kilograms of particulates per body weight than babies and adults.

In the case of 21 year old (herein referred to as adult), the deposition fractions were $0.1179,0.2325,0.4477$ for the head $\mathrm{TB}$, and pulmonary sections respectively 
while the total deposition fraction was observed as 0.7981 for particulates of 32 nm diameter.

For comparison purposes, regional deposition predictions for pyrolysis of Croton megalocarpus biodiesel (aerodynamic diameter of $\sim 22 \mathrm{~nm}$ ) particulate matter were done for similar age groups (Figure 2(a) and Figure 3(b) and Figure 4(a)). The Total lung deposition for 21 years (adult), 8 year and 3 months old were predicted to be $0.7981,0.8580$ and 0.7802 respectively. Evidently, the regional depositions shows high particulate depositions in the pulmonary region compared to the rest of the respiratory systems. This could be attributed to high difusibility of the ultrafine particles compared to coarse particles. The size of the particles in croton $P M \simeq 22 \mathrm{~nm}$ are slightly smaller than in the biodiesel blend $\mathrm{PM} \simeq 32 \mathrm{~nm}$. This is clearly shown by high total depositions in respiratory regions in Figure 2(a) and Figure 3(a) and Figure 4(b) for all age groups as compared to Figure 2(b), Figure 3(b) and Figure 4(a). The difference in total deposition in this study could be attributed to airway geometry, particulate matter size and deposition patterns. The effects of particulate matter in inspiration process can be prevented by minimizing combustion events that have a serious medical impact on the environment and public health. Promotion of clean energy combustion is perhaps the most important measure against hazardous emissions from thermal events.

The major patterns affecting particulate deposition are sedimentation, diffusion and impaction hence this modelling work predicts the dose of inhaled PM and finds out the sections in the respiratory system where there is possible occurrence of toxicity. It is noticeable that blending biodiesel increase particulate sizes and remarkably lowers the risk of inhalation, even though in this study the increase in size is still within the ultrafine category. Thus, extremely ultrafine particulate matter reported in this work is toxic to humans and especially to residents living in polluted cities and industry.

\section{Conclusion}

This study has established that the particulate emissions from the thermal degradation of croton biodiesel and croton biodiesel/commercial diesel blend are ultrafine and can be transported deeply in the respiratory system, and circulated to other body tissues, and hence may cause cardio-pulmonary deaths, oxidative stress, nervous system impairment as well as chronic coughs and cancers which are detrimental to human life. MPPD Ver. 3.04 runs indicated that pulmonary tissue retained the highest ratio of thermal emissions of croton bio-oil particulates for all ages (infants, 8 years and 21 years respectively) as compared to the particulates from the pyrolysis diesel mixtures. Clearly, infants retain a high fraction of particulates possibly because their lungs are not well developed and this may be a major pre-cursor for child mortality. Additionally, blending biodiesel in the correct ratios may be one of the measures of mitigating against environmental pollution caused by transport fuels. Therefore, there is every reason 
to appreciate that clean energy combustion is important towards improving public health and reducing disease burden caused by thermal emissions of varying chemical nature and size.

\section{Acknowledgements}

The authors wish to thank the University of Kwa Zulu-Natal (UKZN), for according JK the opportunity to conduct Scanning electron microscopy. Egerton University is also appreciated for facilitating the success of this study. Applied Research Associates (ARA), Inc., Albuquerque, NM, are greatly appreciated for providing us with MPPD Ver. 3.04 software used in the respiratory simulation of deposition and clearance of particulates from combustion of transport fuels.

\section{Conflicts of Interest}

The authors declare that they have no conflict of interest regarding the publication of this article.

\section{References}

[1] Apte, J.S., et al. (2018) Ambient PM2.5 Reduces Global and Regional Life Expectancy. Environmental Science \& Technology Letters, 5, 546-551. https://doi.org/10.1021/acs.estlett.8b00360

[2] Donahue, N.M. (2018) Air Pollution and Air Quality. In: Green Chemistry, Elsevier, Amsterdam, 151-176. https://doi.org/10.1016/B978-0-12-809270-5.00007-8

[3] Tecer, L.H., et al. (2008) Effect of Meteorological Parameters on Fine and Coarse Particulate Matter Mass Concentration in a Coal-Mining Area in Zonguldak, Turkey. Journal of the Air \& Waste Management Association, 58, 543-552. https://doi.org/10.3155/1047-3289.58.4.543

[4] Cohen, J.M., et al. (2014) An Integrated Approach for the In Vitro Dosimetry of Engineered Nanomaterials. Particle and Fibre Toxicology, 11, 20. https://doi.org/10.1186/1743-8977-11-20

[5] Cohen, A.J., et al. (2017) Estimates and 25-Year Trends of the Global Burden of Disease Attributable to Ambient Air Pollution: An Analysis of Data from the Global Burden of Diseases Study 2015. The Lancet, 389, 1907-1918. https://doi.org/10.1016/S0140-6736(17)30505-6

[6] Terzano, C., et al. (2010) Air Pollution Ultrafine Particles: Toxicity beyond the Lung. European Review for Medical and Pharmacological Sciences, 14, 809-821.

[7] Chen, C.W., et al. (2018) Causality Test of Ambient Fine Particles and Human Influenza in Taiwan: Age Group-Specific Disparity and Geographic Heterogeneity. Environment International, 111, 354-361. https://doi.org/10.1016/j.envint.2017.10.011

[8] Hosgood III, H.D., et al. (2011) Household Coal Use and Lung Cancer: Systematic Review and Meta-Analysis of Case-Control Studies, with an Emphasis on Geographic Variation. International Journal of Epidemiology, 40, 719-728. https://doi.org/10.1093/ije/dyq259

[9] Burnett, R.T., et al. (2014) An Integrated Risk Function for Estimating the Global Burden of Disease Attributable to Ambient Fine Particulate Matter Exposure. Environmental Health Perspectives, 122, 397. https://doi.org/10.1289/ehp.1307049 
[10] Madaniyazi, L., et al. (2015) Projecting Fine Particulate Matter-Related Mortality in East China. Environmental Science \& Technology, 49, 11141-11150. https://doi.org/10.1021/acs.est.5b01478

[11] Maji, K.J., et al. (2018) Estimating Premature Mortality Attributable to PM2.5 Exposure and Benefit of Air Pollution Control Policies in China for 2020. Science of the Total Environment, 612, 683-693. https://doi.org/10.1016/j.scitotenv.2017.08.254

[12] Miller, F.J., et al. (2016) Improvements and Additions to the Multiple Path Particle Dosimetry Model. Journal of Aerosol Science, 99, 14-26. https://doi.org/10.1016/j.jaerosci.2016.01.018

[13] Manojkumar, N., et al. (2019) Application of Multiple-Path Particle Dosimetry Model for Quantifying Age Specified Deposition of Particulate Matter in Human Airway. Ecotoxicology and Environmental Safety, 168, 241-248. https://doi.org/10.1016/j.ecoenv.2018.10.091

[14] Kibet, J.K., et al. (2018) Free Radicals and Ultrafine Particulate Emissions from the Co-Pyrolysis of Croton Megalocarpus Biodiesel and Fossil Diesel. Chemistry Central Journal, 12, 89. https://doi.org/10.1186/s13065-018-0458-6

[15] Pongjanta, J., et al. (2008) Enzymes-Resistant Starch (RS III) from Pullulanase-Debranched High Amylose Rice Starch. Kasetsart Journal of Natural Science, 42, 198-205.

[16] Konert, M. and Vandenberghe, J. (1997) Comparison of Laser Grain Size Analysis with Pipette and Sieve Analysis: A Solution for the Underestimation of the Clay Fraction. Sedimentology, 44, 523-535.

https://doi.org/10.1046/j.1365-3091.1997.d01-38.x

[17] Asgharian, B., et al. (2001) Particle Deposition in a Multiple-Path Model of the Human Lung. Aerosol Science \& Technology, 34, 332-339. https://doi.org/10.1080/02786820119122

[18] Asgharian, B., et al. (2014) Computational Modeling of Nanoscale and Microscale Particle Deposition, Retention and Dosimetry in the Mouse Respiratory Tract. Inhalation Toxicology, 26, 829-842. https://doi.org/10.3109/08958378.2014.935535

[19] Sahu, S., et al. (2013) Particle Size Distribution of Mainstream and Exhaled Cigarette Smoke and Predictive Deposition in Human Respiratory Tract. Aerosol and Air Quality Research, 13, 324-332. https://doi.org/10.4209/aaqr.2012.02.0041 